\title{
SEISMIC VULNERABILITY ASSESSMENT OF FES MEDINA IN MOROCCO
}

\author{
S. Stefanini ${ }^{1, *}$, L. Rovero ${ }^{1}, \mathrm{U}_{\text {. Tonietti }}{ }^{1}$ \\ ${ }^{1}$ DIDA, Università degli Studi di Firenze, Italy - (sara.stefanini, luisa.rovero, ugo.tonietti)@unifi.it
}

Commission II - WG II/8

KEY WORDS: Historic city centres, Seismic vulnerability assessment, Vulnerability index method, Damage scenarios, Medina of Fes

\begin{abstract}
:
The assessment of seismic vulnerability in the Maghreb area is not yet fully investigated, especially considering the important connection between the vulnerability and traditional housing or construction local types. This paper proposes a methodology for the assessment of seismic vulnerability at territorial scale that is calibrated on the specific characteristics of historical settlements in the North of Morocco, mostly made of patio buildings in aggregate. The proposed methodology is structured to be extended and replicated in other similar contexts and is based on the Vulnerability Index approach proposed by the National Group for Earthquake Defence (Gruppo Nazionale per la Difesa dai Terremoti, GNDT). This method was applied to the Medina of Fes, UNESCO World Heritage site, which has suffered severe damages from historical earthquakes. The study allowed the realization of vulnerability and fragility curves, damage scenarios for different seismic intensity and loss scenarios. The proposed methodology was applied a second time to the case study after a simulated structural retrofitting intervention. The results of this second application allowed to validate the guidelines and the reinforcement strategies calibrated on local construction culture. The results of the vulnerability assessment are also presented through maps in the Geographic Information System (GIS) environment.
\end{abstract}

\section{INTRODUCTION}

The Maghreb countries are characterized by a highly valuable cultural heritage. This heritage consists of historical cities, monuments and vernacular settlements and is often realized with techniques and materials that are the result of local cultures whose vulnerability is very high. The loss of traditional knowledge and the uncritical use of incompatible technological cultures as well as natural hazards, in particular seismic events, are threatening the heritage. Morocco, for example, has suffered numerous destructive historical earthquakes and many cities have been partially or largely destroyed (Cherkaoui et al. 2007): Agadir (1731, 1761), Marrakech (1719, 1755), Meknes (1624, 1755), Melilla (1821, 1848), Rabat-Salé (1755), Tangier (1755, 1773). In recent years, events like the one in Agadir in 1960 (M $=5.7)$ and the seismic sequence of Al Hoceima in $1994(\mathrm{M}=$ 6.0), $2004(M=6.4)$ and $2016(M=6.3)$ have shown how the consequences on the population in terms of deaths and injuries and on the built-up area should not be underestimated.

The consequences of past seismic events in Morocco provides evidence of the extreme vulnerability of the buildings in spite of moderate seismicity (Cherkaoui, El Hassani, 2012). Consequently, prevention is particularly important as it is always the most effective tool of protection against earthquakes. In this sense, models capable of predicting the damage caused by earthquakes, whether expressed in terms of human lives or economic losses, are of fundamental importance. These models can predict the economic impact of future earthquakes, support cost/benefit analyses related to consolidation and retrofitting of buildings and help in emergency management.

Over the years different types of models have been developed for assessing the propensity of buildings to being damaged in case of an earthquake, aiming to mitigate the seismic risk. This work proposes an approach for the evaluation of seismic vulnerability of masonry buildings in aggregate with reference to building typologies of Islamic cities, which are basically aggregate patio houses (Figure 1). The method has been applied to the case study of the medina of Fes, UNESCO World Heritage site since 1981. The medina constitutes a complex and stratified urban system and it is an emblematic example of the processes and dynamics in place that risk endangering the Maghreb architectural heritage.

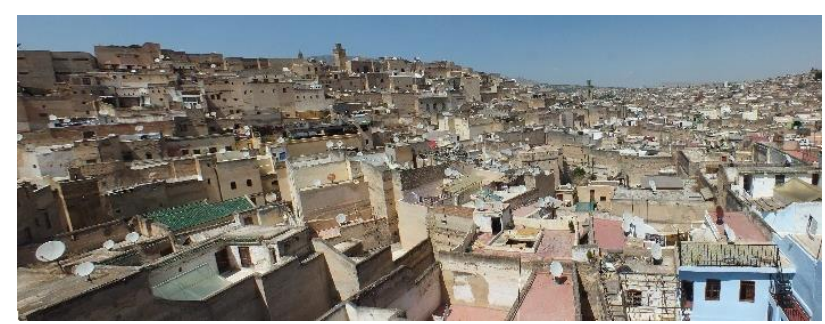

Figure 1. Panoramic view of Fes medina.

\section{CONTEXT OF CASE STUDY}

The city of Fes is located at the eastern end of the Fes-Meknes basin, at the foot of the Rif mountain range. This area is characterized by the complexity of the tectonic margin between the African and Eurasian plates and it is currently considered the most seismic region of the western Mediterranean. Along the Southern Rif Front, at least four moderate-to-severe earthquakes have been documented historically since the 11 th century, some of which occurred in the region comprising the cities of Fes and Meknes. Historical chronology of the seismic events that affected the city of Fes shows how the city was largely destroyed following the seismic events of 1522, 1624 and 1755 (Figure 2).

As always happens in areas subjected to frequent seismic events, the local constructive culture has developed and adopted new specific construction techniques able to give earthquakes resistance to buildings. In particular, the "fassi" building culture has adopted the following anti-seismic techniques:

* Corresponding author 


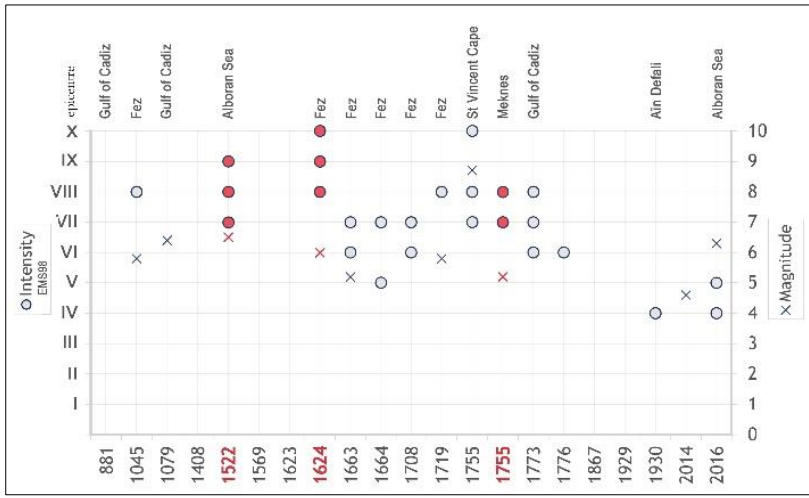

Figure 2. Fes Earthquake Chronology (Cherkaoui e Asebriy, 2003), (El Alami et al., 2004), (El Alami et al., 2005), (Peláez et al., 2007), (Cherkaoui e El Hassani, 2012), (Cherkaoui et al., 2017), earthquake.usgs.gov.

- contrast arches and vaults, which allow the transmission of horizontal action between the connected buildings;

- covered passages (Figure 3a), extensions to the raised floors of the houses, that become galleries at street level;

- drain arches, which "lighten" the weights on the lintels of the openings and distribute the load above them to the sides;

- wooden elements inside the wall structure (Figure 3b). Despite differences, this technique is very similar to that found within the Casbah of Algiers (Abdessemed-Foufa, 2016);

- wooden chains, a technique used exceptionally and reserved for large and important buildings;

- "seismic isolators" (Figure 3c). Inside the patio of the Attarine Medersa it is possible to observe those that seem to be seismic "isolators". They are made up of metal plates placed between the capital and the stem and between the stem and the base of the patio pillars. This technique is similar to that found in the Dey Palace in Algiers (Rovero and Tonietti, 2012).

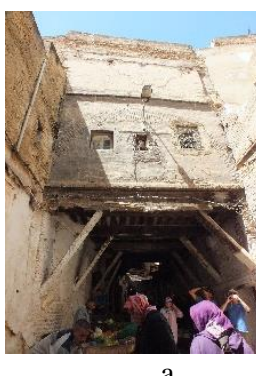

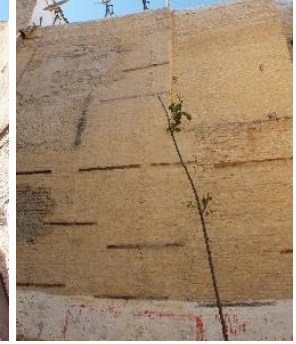

b

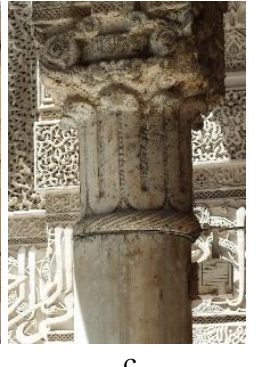

Figure 3. Some traditional anti-seismic techniques in Fes: a) covered passage with a discharging arc; b) wooden element in the masonry; c) "seismic isolator" in Attarine Medersa.

During the inspections and visits to Fes medina, various types of recurrent and systematic damage were observed and diagnosed. The most widespread and worrying failure within the medina is constituted by the "bulging", both vertical and horizontal, sign of the activation of bending mechanisms. Another type of extremely widespread damage is represented by the systems of diagonal cracks that mainly involve the covered passages. Furthermore, numerous buildings within the medina show a high level of degradation.

The problems afflicting the building can be substantially traced back to the following diagnostic categories:
- weaknesses related to the architectural typology of the patio house;

- over-utilization and over-densification of the building, which lead to unforeseen overloads for the original building;

- lack of maintenance (mainly due to the abandonment of the house by the owners or the impossibility of carrying out restoration works due to lack of economic resources);

- problems of water infiltration and rising damp, which lead to the degradation of materials;

- subsidence of the soil.

The situation is further aggravated by the introduction of transformations and modifications, some of which are clearly visible because they are made with materials and techniques that are not compatible with the original buildings. Finally, the vulnerability is increased by the collapse of a number of buildings that lead to many empty spaces within the medina. This greatly weakens the neighbouring buildings, depriving them of the beneficial effect of the aggregate system.

Within the large urban aggregate of Fes medina, two areas were chosen to be the subject of in-depth study (Figure 4). They have been chosen for their representativeness with respect to the architectural typologies of the medina, considering the different traditional materials, the characteristics of the structural systems, the main critical issues and the typical situations of degradation and damage found in the entire medina.

The quality of the data to be collected for the vulnerability assessment was judged according to the indications of previous guidelines (Rossetto et al., 2014) in order to obtain significant vulnerability and fragility curves. Since the present research could not take advantage of post-seismic data, particular attention was paid to the design and execution of information gathering, in order to guarantee an acceptable data quality.

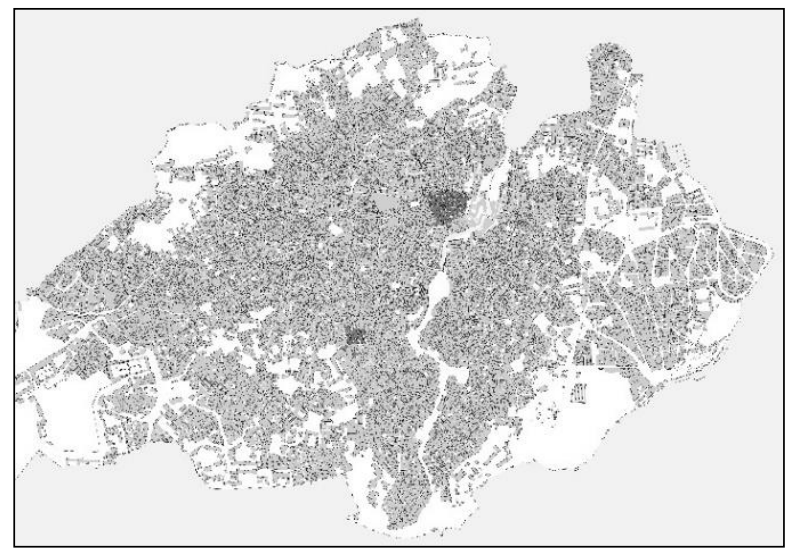

Figure 4. Medina plan with sample blocks.

\section{SEISMIC VULNERABILITY ASSESSMENT}

The purpose of the seismic vulnerability assessment is to obtain the probability of a level of damage for a certain type of building, due to a certain earthquake scenario. The evaluation of seismic risk in Morocco is still not sufficiently studied, especially if it is considered indispensable to relate it to the housing and construction typologies that characterize that area and culture. Morocco building vulnerability studies use the LM1 RISK-UE method (El Hammoumi et al., 2009; Cherif et al., 2015, Cherif et al., 2018), based on the implicit vulnerability model (qualitative damage matrices) included in the European Macroseismic Scale (EMS-98) and conceived for the assessment of seismic vulnerability in European contexts. 
Since it was not possible to use post-seismic data, the method adopted for the vulnerability analysis in this work is the Vulnerability Index (Benedetti, Petrini, 1984). This method allows to determine the building vulnerability by means of parameters taking into account particularities and problems linked to the local context, instead of using only the building type (as required by the macroseismic method, for example).

An important update of the Vulnerability Index method has been proposed in a previous work (Vicente, 2008) in which three different levels of analysis has been considered: building, façade and aggregate. Other works (Formisano, Mazzolani, 2009; Formisano et al., 2011) introduced important parameters describing the interaction of the building with the aggregate, following the consideration that the original method (Benedetti, Petrini, 1984) is inappropriate for buildings inside a building complex. Subsequently, many studies have been carried out by applying the method of the Vulnerability Index in aggregate masonry contexts (Neves et al., 2012; Ferreira et al., 2013; Athmani et al., 2015, 2018; Maio et al., 2016; Formisano et al., 2017).

\subsection{Proposed methodology}

The proposed assessment method for the aggregate masonry buildings in Maghreb is a hybrid method: it combines the technique of vulnerability index, detected through different parameters (Benedetti, Petrini, 1984), with the vulnerability functions used in the macroseismic method (Giovinazzi, Lagomarsino, 2004).

The procedure is based essentially on the GNDT II level approach proposed by the National Group for Earthquake Defense (GNDT, 1994), for the vulnerability assessment of residential masonry buildings. The method is based on postseismic damage observation and survey data covering a vast area, focussing on the most important parameters affecting buildings damage which must be surveyed individually. The GNDT procedure has been adapted here for use with Maghreb masonry buildings in aggregates and it was improved by:

(i) the reorganization and simplification of the vulnerability form. This has pursued two main objectives. The first one is the adaptability of the investigation strategy to a wide range of construction systems and architectural features: this allows to use the procedure in different contexts, but still similar to that analysed in this work. The second one is the operability on the scale of the aggregate: the building is described in order to consider its specific characteristics, but generalizing enough not to evaluate particular situations.

(ii) the introduction of new parameters that take into account the particular construction features of the studied area and the interaction between buildings. The good level of information on building stock has allowed to redefine some of the criteria describing the vulnerability for the parameters.

The detection of the various vulnerability factors takes place through 20 parameters grouped in five different sections concerning respectively: resistant system, floors and roofing system, irregularities, interactions within the aggregate, state of conservation and other elements (see Table 1). Overall vulnerability is calculated as the weighted sum of the parameters. For each parameter it is necessary to express a judgment through 4 classes of increasing vulnerability (A, B, C, D). Each parameter has a weight associated with it. Once the vulnerability class has been assigned to each parameter, it is possible to obtain the partial vulnerability index, $\mathrm{I}_{v} *$ according to the formula:

$$
I_{v}^{*}=\sum_{i=0}^{20} C_{v i} \times P_{i}
$$

where $\mathrm{C}_{\mathrm{vi}}$ is the score associated with each vulnerability class (A, $\mathrm{B}, \mathrm{C}$ and $\mathrm{D})$ and $\mathrm{P}_{\mathrm{i}}$ is the weight attributed to each parameter. The value of the vulnerability index $I_{v}$ is achieved from normalization in the range from 0 to 100 of $\mathrm{I}_{v} *$ (where 0 represents no vulnerability and 100 represents the maximum vulnerability). With regard to the attribution of the relative weights, the parameters considered in this proposal have been evaluated with respect to their importance in structural behaviour, in analogy to what was proposed in the original method (Benedetti, Petrini, 1984).

\begin{tabular}{|c|c|c|c|c|c|}
\hline \multirow{2}{*}{ Parameters } & \multicolumn{4}{|c|}{ Class $\mathrm{C}_{\mathrm{vi}}$} & \multirow{2}{*}{$\begin{array}{c}\text { Weight } \\
\mathrm{p}_{\mathrm{i}}\end{array}$} \\
\hline & A & $\mathrm{B}$ & $\mathrm{C}$ & $\mathrm{D}$ & \\
\hline \multicolumn{6}{|c|}{ Section 1 - Structural building system } \\
\hline 1.1 Type of resisting system & 0 & 5 & 25 & 50 & 0,75 \\
\hline $\begin{array}{l}1.2 \text { Quality of the resisting } \\
\text { system }\end{array}$ & 0 & 5 & 25 & 50 & 1,2 \\
\hline 1.3 Number of floors & 0 & 15 & 25 & 50 & 1,2 \\
\hline 1.4 Maximum slenderness & 0 & 5 & 25 & 50 & 1,5 \\
\hline $\begin{array}{l}1.5 \text { Maximum distance } \\
\text { between walls }\end{array}$ & 0 & 5 & 25 & 50 & 1,5 \\
\hline \multicolumn{6}{|c|}{ Section 2 - Floor slabs and roofs } \\
\hline 2.1 Horizontal diaphragms & 0 & 5 & 25 & 50 & 0,75 \\
\hline 2.2 Roofing system & 0 & 15 & 25 & 50 & 0,75 \\
\hline \multicolumn{6}{|c|}{ Section 3 - Irregularities } \\
\hline $\begin{array}{l}3.1 \text { Building location and } \\
\text { foundations }\end{array}$ & 0 & 15 & 25 & 50 & 1,2 \\
\hline 3.2 Foreparts & 0 & 5 & 25 & 50 & 1 \\
\hline 3.3 Plan configuration & 0 & 5 & 25 & 50 & 1,5 \\
\hline 3.4 Portico surfaces & 0 & 5 & 25 & 50 & 1,2 \\
\hline $\begin{array}{l}3.5 \text { Area of openings and } \\
\text { alignments }\end{array}$ & 0 & 5 & 25 & 50 & 0,75 \\
\hline $\begin{array}{l}\text { 3.6 Presence of staggered } \\
\text { floors }\end{array}$ & 0 & 15 & 25 & 45 & 0,75 \\
\hline 3.7 Turrets & 0 & 5 & 25 & 50 & 1,5 \\
\hline \multicolumn{6}{|c|}{ Section 4-Aggregate interaction } \\
\hline 4.1 Altimetric interaction & -20 & 0 & 15 & 45 & 1 \\
\hline 4.2 Planimetric interaction & -45 & -25 & -15 & 0 & 1,5 \\
\hline $\begin{array}{l}\text { 4.3 Typological and structural } \\
\text { discontinuity }\end{array}$ & -10 & 0 & 10 & 45 & 1,2 \\
\hline \multicolumn{6}{|c|}{ Section 5 - Conservation status and other elements } \\
\hline 5.1 Non-structural elements & 0 & 5 & 20 & 45 & 0,25 \\
\hline $\begin{array}{l}5.2 \text { Interventions and changes } \\
\text { to the original system }\end{array}$ & -10 & 0 & 25 & 50 & 1,5 \\
\hline $\begin{array}{l}5.3 \text { General state of } \\
\text { conservation }\end{array}$ & 0 & 5 & 25 & 50 & 1,5 \\
\hline
\end{tabular}

Table 1 . The proposed Vulnerability index method.

\subsection{Vulnerability assessment: results, damage and loss scenarios}

The buildings sample on which the survey was carried out consists of a total of 34 brick masonry buildings. The obtained sample represents a medium quality database (Rossetto et al., 2014). Particular attention was paid to the design and execution of the information collection form and a detailed survey of the buildings was carried out. This was made to limit as much as possible the uncertainty arising from the number of analysed buildings and to ensure acceptable data quality. For each analysed building, a vulnerability judgment was expressed according to the different parameters and, subsequently, a vulnerability index was calculated according to Equation (1) 
The mean value of the vulnerability index of the sample examined is 37.61 , the standard deviation is 7.67 and the coefficient of variation is $20.4 \%$. Analysis of the results shows that the whole sample has a vulnerability index greater than 20 , which is equivalent to a class B vulnerability according to EMS-98. Approximately $12 \%$ of buildings have a vulnerability index higher than 45, equivalent to class A (Giovinazzi, Lagomarsino, 2004). Figure 5 shows the distribution histogram for the obtained indices. The values suggest that the sample vulnerability is moderately high. The spatial distribution of the vulnerability indices is shown in Figure 6, through representation in the GIS environment. From the maps it is possible to observe that corner buildings have the highest levels of vulnerability (Iv> 45) and this is due precisely to their location on the edge of the building aggregate. This indicates how priority should be given to intervention and reinforcement actions, paying particular attention to corner buildings.

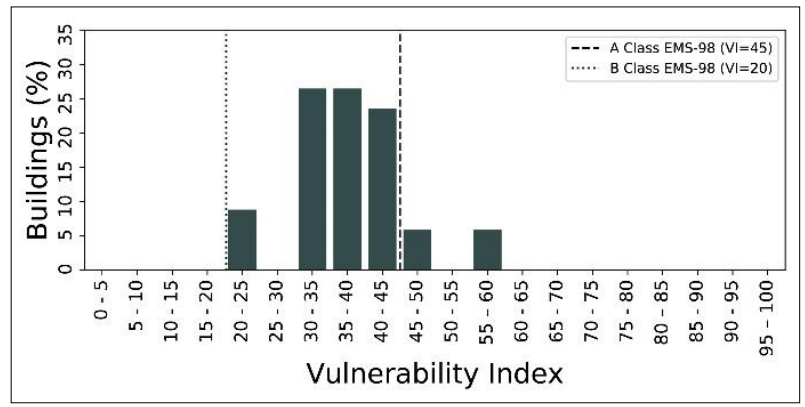

Figure 5. Distribution histogram of vulnerability index.
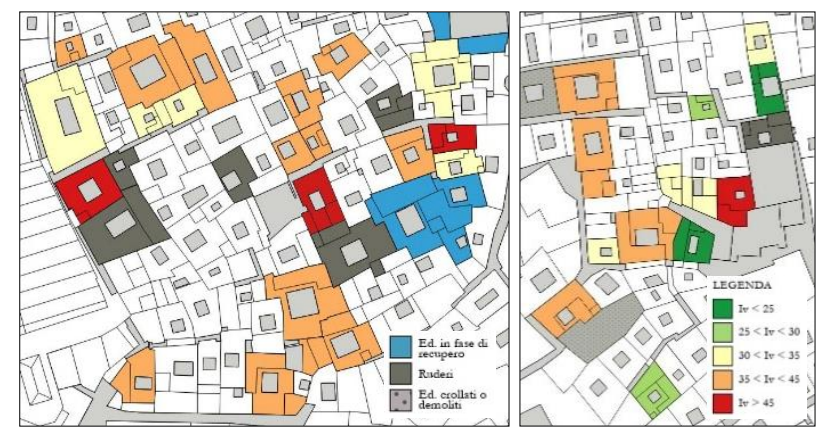

Figure 6. Spatial distributions of the vulnerability index.

\subsubsection{Damage estimation and fragility curves.}

Once the vulnerability index has been assessed, the mean damage grade, $\mu_{\mathrm{D}}$, can be estimated through the following equation (Bernardini et al., 2007):

$$
\mu_{D}=2.5+3 \times \tanh \left(\frac{I+6.25 \times V-12.7}{Q}\right) \times f(V, I) \quad 0 \leq \mu_{\mathrm{D}} \leq 5
$$

where I represents the macroseismic intensity, $\mathrm{V}$ is the vulnerability index, $Q$ is a ductility factor and $f(V, I)$ is a function introduced to understand the trend of vulnerability curves derived from EMS-98 DPM for low macroseismic intensity values. It is defined as follows:

$$
f(V, I)=\left\{\begin{array}{r}
e^{V / 2 \times(I-7)}, I \leq 7 \\
1, I>7
\end{array} \quad 0 \leq \mu \mathrm{D} \leq 5\right.
$$

The vulnerability curve position relative to the abscissa is determined by index $\mathrm{V}$, while the slope is defined by the ductility factor $\mathrm{Q}$ for a given construction type. For masonry buildings the value of $Q$ is between 1.5 and 3.0. In this work, a ductility factor of 2.3 was considered. The value of the mean damage grade $\mu_{\mathrm{D}}$, which will be between 0 and 5 , depends on the vulnerability index $\mathrm{V}$, related with $\mathrm{I}_{\mathrm{v}}$ through the equation:

$$
\mathrm{V}=0,56+0,0064 \times \mathrm{I}_{\mathrm{v}}
$$

This correlation was firstly proposed on the basis of data taken from the Portuguese historical construction (Vicente et al., 2011). It should be calibrated on the basis of the data related to the Maghreb construction in order to have a more effective validity of the presented methodology. It was considered reasonable to use Equation (4) following its application to the case study of the Algerian city of Annaba, characterized by a historical construction similar to that considered in this work (Athmani et al., 2015, 2018); this due to the lack of systematic information on seismic damage in masonry construction in Morocco to establish correlations between vulnerability and expected damage.

Figure 7 shows the vulnerability curves obtained for events with different macroseismic intensities defined by the EMS-98 scale (Grünthal, 1998). They were calculated considering the average value of the Vulnerability Index of the analysed sample ( $\mathrm{V}_{\text {mean }}=$ 37.61) and for other characteristic values of the distribution that are $\mathrm{Iv}_{\mathrm{m}}-2 \sigma, \mathrm{Iv}_{\mathrm{m}}-\sigma, \mathrm{Iv}_{\mathrm{m}}+\sigma, \mathrm{Iv}_{\mathrm{m}}+2 \sigma$.

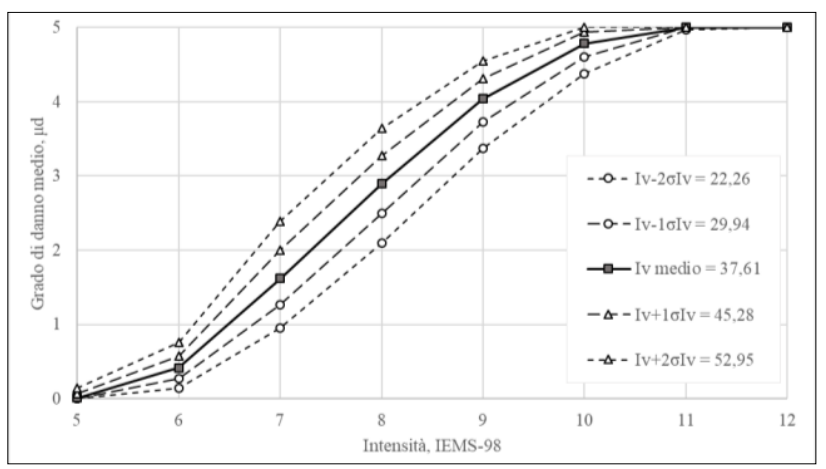

Figure 7. Vulnerability curves for the buildings sample.

Thanks to the mean damage grade, $\mu \mathrm{D}$, it is possible to define damage histograms on a probabilistic basis for different seismic intensities and vulnerability values. Beta probability function was used to construct these damage distribution histograms which, since it can be controlled by parameters defining its form ( $t$ and $r$ ), allows a regulation of the function in relation to the damage distribution resulting from more detailed studies (Giovinazzi, 2005). The equation of the continuous beta probability function is as follows:

$$
P D F: p_{\beta}(x)=\frac{\Gamma(t)}{\Gamma(r) \Gamma(t-r)} \frac{(x-a)^{r-1}(b-x)^{t-r-1}}{(b-a)^{t-1}} \quad a \leq x \leq b
$$

where $a$ and $b$ are the boundaries of the distribution and $\Gamma$ is the gamma function. According to the same parameters, the mean value $\mu_{\mathrm{x}}$ of the continuous variable $\mathrm{x}$, which varies between a and $\mathrm{b}$, and its variance $\sigma_{\mathrm{x}}^{2}$ are defined as follows:

$$
\begin{aligned}
& \mu_{x}=a+\frac{r}{t}(b-a) \\
& \sigma_{x}^{2}=(b-a)^{2} \frac{r(b-a)}{t^{2}(t+1)}
\end{aligned}
$$

The parameters $t$ and $r$ (or equivalently the mean and variance) control the shape of the distribution. Low values of $t$ give wide distributions while high values give narrow distributions. In this study $\mathrm{t}=8$ was used. 
To use the beta distribution, it is necessary to refer to the degrees of damage $D_{k}$, with $\mathrm{k}$ between 0 and 5 . For this purpose, it is advisable to assign the value 0 to parameter a and the value 6 to parameter b. Starting from this assumption, it is possible to calculate the probability associated with the degree of damage $\mathrm{k}$ as follow:

$$
p_{k}=\int_{k}^{k+1} p_{\beta}(y) d y=P_{\beta}(k+1)+P_{\beta}(k)
$$

Following this definition, the mean damage grade, $\mu_{\mathrm{D}}$, can be correlated with the mean value of the beta distribution, $\mu_{\mathrm{x}}$, through the equation:

$$
\mu_{x}=0.042 \mu_{D}^{3}-0.31 \mu_{D}^{2}+1.72 \mu_{D}
$$

Through Equations (6) and (9) it is possible to correlate the two parameters of the beta distribution, $t$ and $r$, with the mean damage grade, $\mu_{\mathrm{D}}$, through the equation (Giovinazzi, 2005):

$$
r=t\left(0.007 \mu_{D}^{3}-0.0525 \mu_{D}^{2}+0.2875 \mu_{D}\right)
$$

For a beta function discrete distribution, the probability associated with each degree of damage, $D_{k}$, with $\mathrm{k} \in[0,5]$, can be defined as follows, using the value of the mean damage grade $\mu_{\text {D }}$ obtained from equation (2):

$$
\begin{aligned}
& P\left(D_{0}\right)=p(0)=\int_{0}^{0.5} k(t, r) \cdot x^{r-1}(5-x)^{t-r-1} d x \\
& P\left(D_{k}\right)=p(k)=\int_{k-0.5}^{k+0.5} k(t, r) \cdot x^{r-1}(5-x)^{t-r-1} d x \\
& \text { with } \mathrm{k}=1,2,3,4 \\
& P\left(D_{5}\right)=p(5)=\int_{4.5}^{5} k(t, r) \cdot x^{r-1}(5-x)^{t-r-1} d x
\end{aligned}
$$

Figure 8 shows the estimate of the damage distributions obtained using the beta distribution $(a=0, b=6, t=8)$, for seismic intensities of VIII and IX for the average value of the vulnerability index $\mathrm{I}_{\mathrm{v}}$. These seismic intensities correspond to those reported by historical sources for seismic events that caused the partial destruction of the medina of Fes (see Figure 2). The damage scenarios for seismic intensity VIII and IX are shown below (Figures 9 and 10) and they were obtained using the GIS tool.

Fragility curves are another way to represent the expected damage. As the vulnerability curves, the fragility curves relate the seismic intensity, expressed through the intensity degrees IEMS-98, and the damage, described according to the five grades defined by the European macroseismic scale (Grünthal, 1998). They define the probability of exceeding a certain degree of damage $D_{k}$ and are obtained directly from the cumulative beta probability function for a given value of Vulnerability Index:

$$
P\left(D \geq D_{k}\right)=1-p_{\beta}(k)
$$

Figure 11 shows the fragility curves obtained for the IVmean.

\subsection{2 - Loss assessment.}

The estimation of losses following seismic events allows to support the processing of seismic risk prevention and management decisions and actions, especially if carried out in relation to the vulnerability of the buildings, to the results of the analysis of the damage scenarios and to implementation in GIS environments. Since the estimate of the losses is strictly connected to the damage levels observed after seismic events, and such data are not available for the studied area, this work uses the approach already used by (Athmani et al., 2018) for the city of Annaba in Algeria. The selected estimate model was proposed by the Italian National Seismic Service (Bramerini et al., 1995).

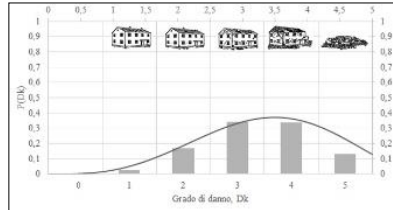

a

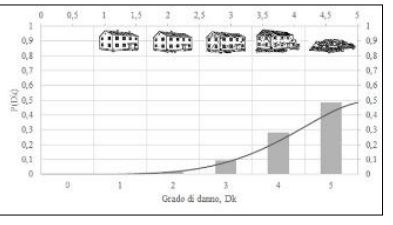

b
Figure 8. Estimate of damage distribution for $\mathrm{Iv}_{\text {mean }}=37.61$ for: (a) IEMS-98 = VIII; (b) IEMS-98 = IX.

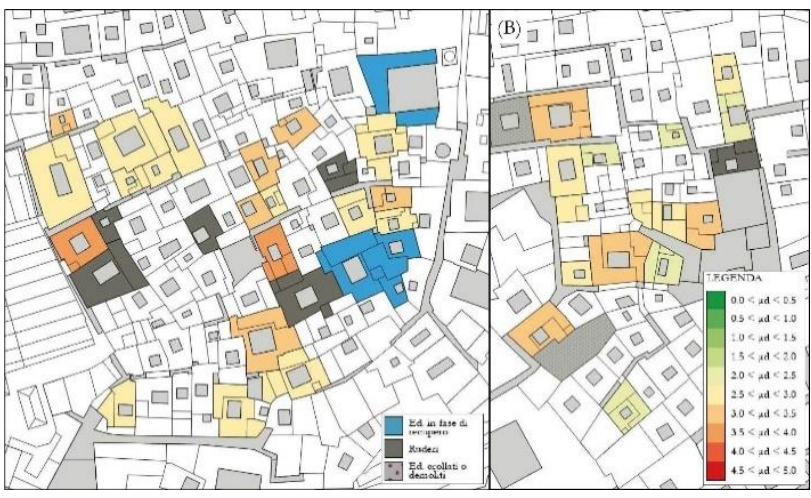

Figure 9. Damage scenario for $\mathrm{I}_{\mathrm{EMS}-98}=\mathrm{VIII}$

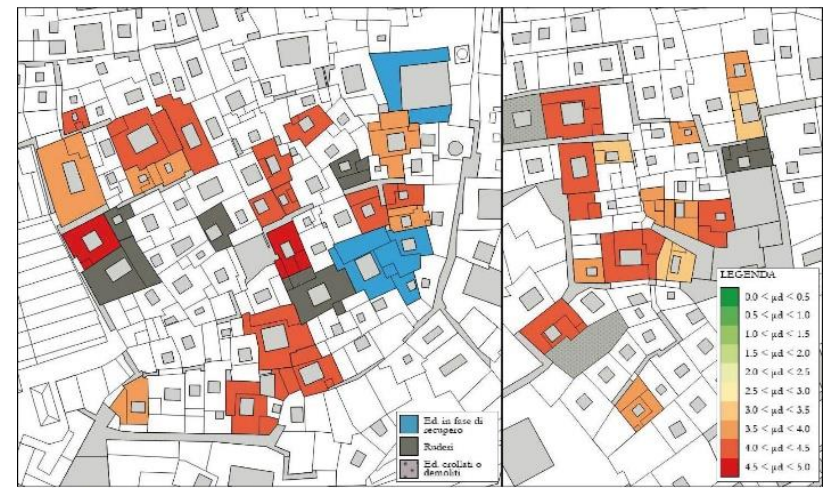

Figure 10. Damage scenario for IEMS-98 =IX.

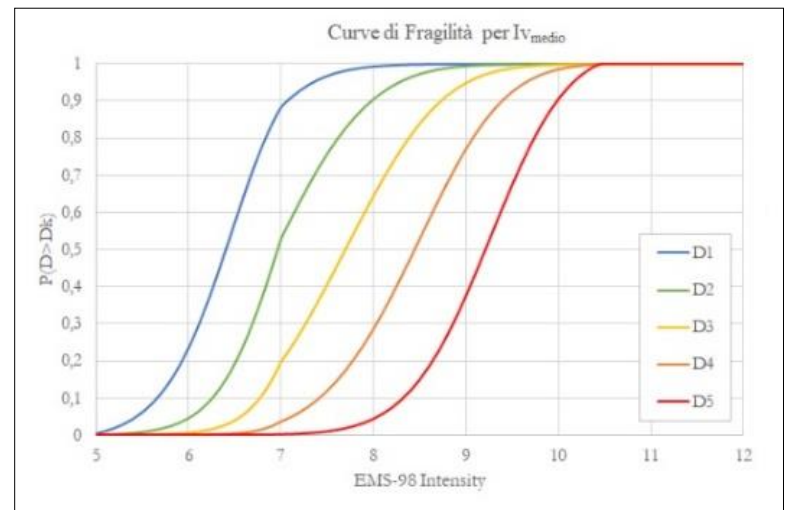

Figure 11. Fragility curves for $I v_{\text {mean }}=37.61$.

This approach was used for losses assessments in terms of collapsed or unusable buildings, as well as for estimates of deceased, seriously injured and homeless people, starting from the previously calculated damage scenarios. The economic losses and the repair costs were not estimated due to the lack of economic data related to the area covered by this study; despite they represent a very important tool in the definition of the choices by the actors involved in the seismic risk management. 
The probabilities associated with the occurrence of a certain damage degree are used to estimate losses and they are influenced by some weights, that are multiplying factors assuming values between 0 and 1. High damage $\left(\mathrm{D}_{5}\right)$ is associated with collapse, while moderate damage ( $\mathrm{D}_{3}$ and $\left.\mathrm{D}_{4}\right)$ is associated with the probability that buildings become unusable. The following equations have been used to estimate collapsed and unusable buildings:

$P_{\text {collapse }}=P\left(D_{5}\right)$

$P_{\text {unusablebuildings }}=P\left(D_{3}\right) \times W_{u b, 3}+P\left(D_{4}\right) \times W_{u b, 4}$

where $P\left(D_{3}\right), P\left(D_{4}\right)$ and $P\left(D_{5}\right)$ are the probabilities of occurrence of the damage $D_{3}, D_{4}$ and $D_{5}$ respectively, and $W_{u b, 3}$ and $W_{u b, 4}$ are the weights associated with the respective probabilities. The SSN procedure (Bramerini et al., 1995) indicates distinct values for these weights. In this work the following values have been used: $\mathrm{W}_{\mathrm{ub}, 3}=0.4$ and $\mathrm{W}_{\mathrm{ub}, 4}=1$ (Athmani et al., 2018). Figure 12 shows the probabilities obtained from the significant vulnerability values $\left(I v_{m}-2 \sigma ; I_{m}-\sigma ; I v_{m e a n}, I_{m}+\sigma ; V_{m}+2 \sigma\right)$. It should be noted that the number of unusable buildings decreases with the intensity as the number of collapsed buildings increases. To estimate the probability of having human losses, serious injuries and homeless the following equations were used:

$P_{\text {dead.and.severely.injured }}=0.3 \times P\left(D_{5}\right)$

$P_{\text {homeless }}=P\left(D_{3}\right) \times W_{u b, 3}+P\left(D_{4}\right) \times W_{u b, 4}+P\left(D_{5}\right) \times W_{u b, 5}$

The coefficients associated with the different probability of damage occurrence are: $\mathrm{W}_{\mathrm{ub}, 3}=0.4, \mathrm{~W}_{\mathrm{ub}, 4}=1.0$ and $\mathrm{W}_{\mathrm{ub}, 5}=0.7$ (Athmani et al., 2018). Figure 13 shows the estimate of the number of victims, serious injuries and homeless associated with significant values of the vulnerability index $\left(\mathrm{Iv}_{\mathrm{m}}-2 \sigma ; \mathrm{Iv}_{\mathrm{m}}-\sigma\right.$; $\left.I v_{\text {mean }}, I v_{m}+\sigma ; I v_{m}+2 \sigma\right)$. It is relevant to note that, as seismic intensity increases, the number of homeless people decreases while the number of deaths and injuries increases.

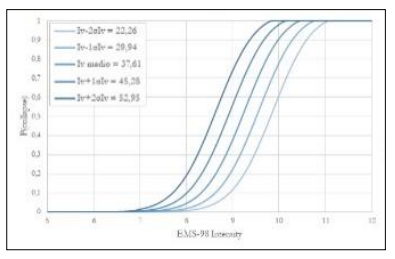

a

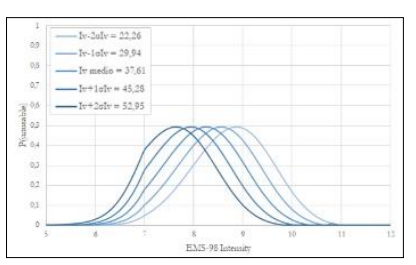

b
Figure 12. Estimative of: a) collapsed buildings; b) unusable buildings

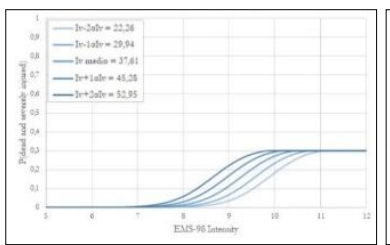

a

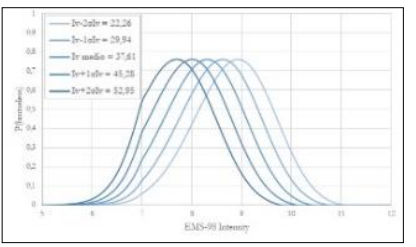

b
Figure 13. Estimative of: a) dead and severely injured; b) homeless.

According to equations (13) and (14), the number of victims and serious injuries is estimated to be $30 \%$ of the population present in collapsed buildings and the number of homeless people is estimated to be $100 \%$ of the population residing in unusable buildings plus the remaining $70 \%$ of inhabitant in collapsed buildings. These percentages, belonging to a simplified procedure, underestimate the impact of a seismic event on the mortality rate and serious injuries since they do not consider, for example, the time when the earthquake may occur (Vicente, 2008) or the high urban density of a building aggregate such as Fes medina one.

\subsection{Vulnerability and damage scenarios as a result of reinforcement interventions}

The vulnerability assessment was applied a second time on the same building sample after a simulated structural retrofitting intervention. The supposed structural consolidation was considered consistent with the construction logic, using homogeneous materials and compatible techniques. This operation was carried out in order to predict the impact that consolidation actions can have in reducing the buildings vulnerability. To simulate the implementation of consolidation interventions, the vulnerability forms related to the examined buildings were recompiled and the Vulnerability Index associated with the sample was calculated again. The new mean value of the vulnerability index is 25.71 with a standard deviation of 5.15 and a coefficient of variation equal to $20 \%$. After the structural reinforcement, the sample vulnerability is significantly reduced, as shown by the distribution histogram of the obtained Indices (Figure 14). The spatial distribution of Indices is shown in Figure 15 and it highlights how the corner buildings would continue to represent one of the major concerns regarding the vulnerability of the aggregate, with Iv between 30 and 35 .

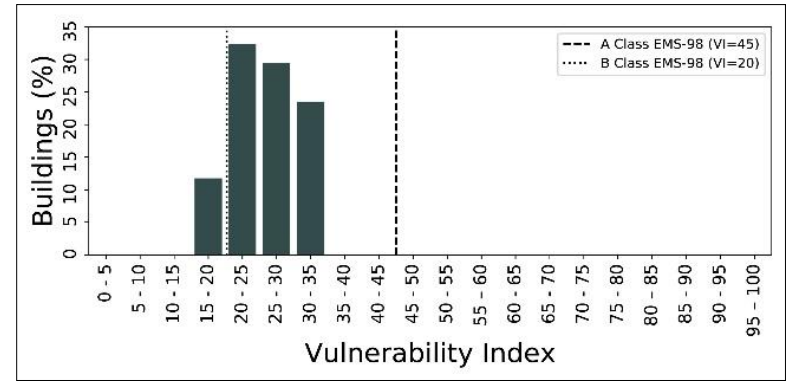

Figure 14. Distribution histogram of vulnerability index after the hypothesis of consolidation.

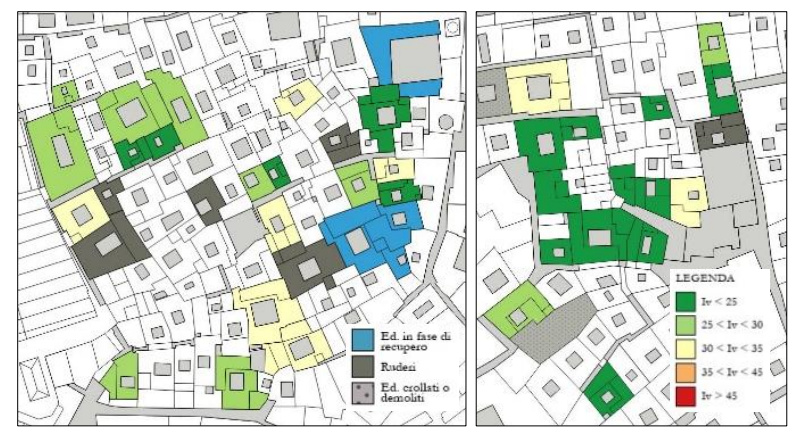

Figure 15. Spatial distributions of the vulnerability index after the hypothesis of consolidation.

Figure 16 shows the vulnerability curves. In Figures 17 and 18, are reported the damage scenarios for seismic actions corresponding to the two degrees of seismic intensity already examined for the actual state, i.e. VIII and IX. The estimated scenarios show that, after the consolidation interventions, the damage decreases by about one degree on the EMS-98 scale for seismic events of the same intensity, compared to the actual situation. The expected damage following the reinforcement was represented also by the fragility curves (Equation 12). Figure 19 shows the curves obtained for the new value of the Ivmean. 


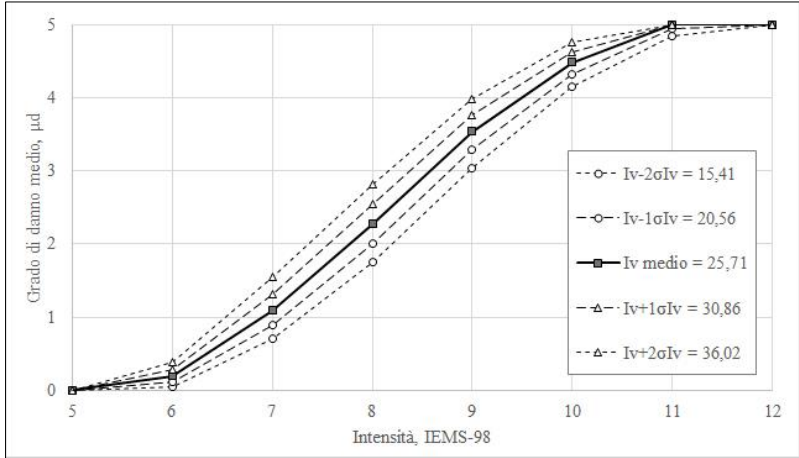

Figure 16. Vulnerability curves for the buildings sample after the hypothesis of consolidation.

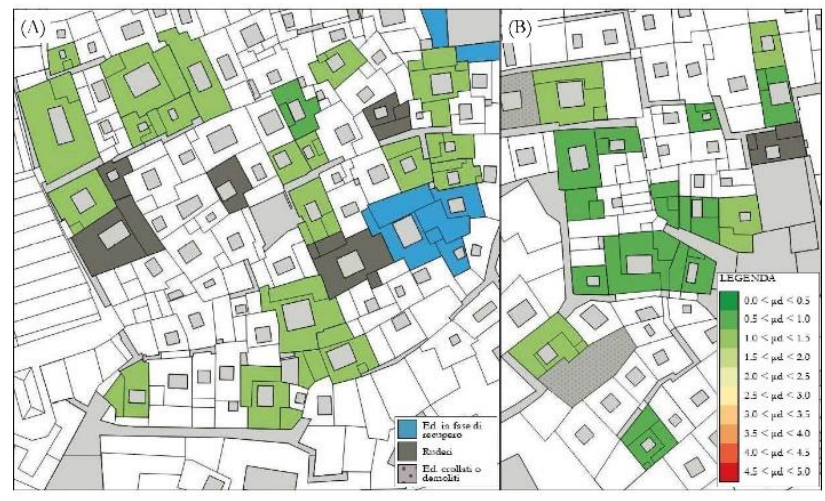

Figure 17. Damage scenario for IEMs-98=VIII after the hypothesis of consolidation.

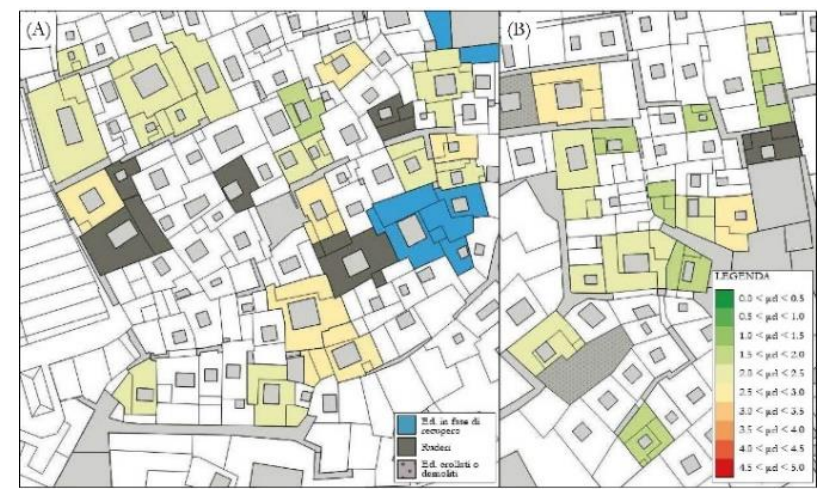

Figure 18. Damage scenario for IEMS-98=IX after the hypothesis of consolidation.

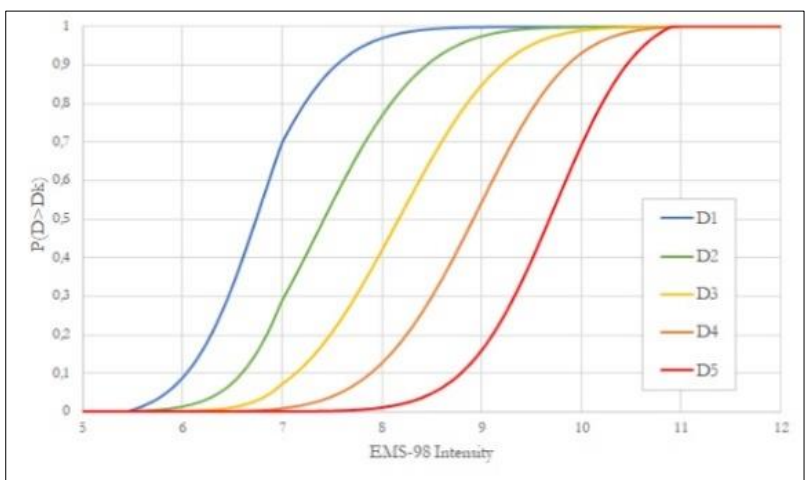

Figure 19. Fragilities curves for $\mathrm{Iv}_{\text {mean }}=25.71$ after the hypothesis of consolidation.

\section{CONCLUSION}

The work focus is the definition of a methodology for seismic vulnerability assessment at the aggregate scale. The method is calibrated on the specificity of historic settlements at risk of disappearance in the Maghreb area. The proposed procedure is based on the GNDT level II vulnerability index method, reaching a high level of adaptability and operability: the analysis strategy can be used in different contexts, characterized by the same housing typology, and it describes the buildings and their critical issues on the scale of the aggregate. The method is therefore applicable to the masonry constructions of the historical settlements consisting of patio buildings in an aggregate. However, it can be used for the investigation of historicized masonry aggregates in contexts different from the Maghreb through a simple modification of the specific characteristics of the buildings to be assessed.

The proposed method allows to identify 20 parameters describing the behaviour and the seismic response of the buildings in aggregates, indirectly identifying the weaknesses and recurring critical issues of the most vulnerable buildings that will require urgent intervention. The proposed procedure, despite relying on a medium quality sample, has a good level of reliability, thanks to the high level of information on the examined buildings and the high level of confidence obtained in the data collection. The method was applied to a sample consisting of 34 buildings within the medina of Fes, allowing to obtain vulnerability and fragility curves, damage scenarios and loss scenarios.

The damage scenarios show that, even in a region with moderate seismic hazard such as the city of Fes, the level of damage can be explained by the high vulnerability of buildings. Widespread and careful consolidation interventions can lead to a significant reduction of the damage level, as indicated by the damage scenarios estimated after structural reinforcement operations.

\section{ACKNOWLEDGEMENTS}

The authors thank Laura D'Isita for the fundamental and competent help in gathering information on the buildings of Fes Medina.

\section{REFERENCES}

Abdessemed-Foufa A. A., 2016. Historic Earthquake-Resistant Constructive Techniques Reinforced by Wooden Logs in Algeria. Historical Earthquake-Resistant Timber Framing in the Mediterranean Area (p. 33-45). Springer, Cham;

Athmani A., Gouasmia A., Ferreira T., Vicente R., 2015. Earthquake Vulnerability and Repair Cost Estimation of Masonry Buildings in the Old City Center of Annaba, Algeria. World Academy of Science, Engineering and Technology, International Journal of Civil, Environmental, Structural, Construction and Architectural Engineering, 9(6), p. 682-688;

Athmani A., Ferreira T. M., Vicente R., 2018. Seismic risk assessment of the historical urban areas of Annaba city, Algeria. International Journal of Architectural Heritage, 12(1), p. 47-62;

Benedetti D., Petrini V., 1984. Sulla vulnerabilità sismica di edifici in muratura: un metodo di valutazione. A method for evaluating the seismic vulnerability of masonry buildings. L'industria delle Costruzioni, (149), p. 66-74; 
Bernardini A., Giovinazzi S., Lagomarsino S., Parodi S., 2007. The vulnerability assessment of current buildings by a macroseismic approach derived from the EMS-98 scale, ANIDIS, XII Convegno Nazionale l'ingegneria sismica in Italia, 10 a 14 Giugno, Pisa;

Bramerini F., Di Pasquale G., Orsini A., Pugliese A., Romeo R., Sabetta F., 1995. Rischio sismico del territorio italiano. Proposta per una metodologia e risultati preliminari. Rapporto tecnico del Servizio Sismico Nazionale, SSN/RT/95/01, Roma;

Cherif S., Chourak M., Abed M., Douiri A., 2018. Potential Seismic Damage Assessment of Residential Buildings in Imzouren City (Northern Morocco). Buildings, 8(12), p. 179;

Cherif S., Chourak M., Abed M., 2015. Seismic risk assessment of the city of Al Hoceima (North of Morocco) using the RISKUE vulnerability index method. Proceedings, 50th International Conference on Earthquake Engineering and Seismology, Kiel, Germany, May (p. 12-16);

Cherkaoui T. E., Asebriy L., 2003. Le risque sismique dans le Nord du Maroc. Trav. Inst. Sci, p. 225-232;

Cherkaoui T. E., El Hassani A., 2012. Seismicity and Seismic hazard in Morocco 1901-2010. Bulletin de l'Institut Scientifique, Rabat, section Sciences de la Terre, 34, p. 45-55.

Cherkaoui T. E., Bensaïd I., Rimi A., Harnafi M., 2007. Le réseau sismologique du département de physique du globe: 1937-2007, Document publié à l'occasion du 70ème anniversaire de l'Observatoire Averroès et du 50ème anniversaire de l'Université Mohammed V-Agdal 1937-2007 ;

Cherkaoui T. E., Medina F., Mridekh A., 2017. Re-examination of the historical 11 May, 1624 Fez earthquake parameters. Fisica de la Tierra, 29, p. 135-157.

El Alami S. O., Tadili B., Brahim L. A., Mouayn I., 2004. Seismicity of Morocco for the period 1987-1994. Pure and Applied Geophysics, 161(5-6), p. 969-982;

El Alami S. O., Tadili B. A., Cherkaoui T. E., Ramdani M., 2005. L'alea sismique et l'amenagement du territoire des provinces du nord du Maroc, Revue AFN Maroc $n^{\circ} 25$;

EL Hammoumi A., Brahim A. I., Birouk A., Toto El A., Mouraouah M. K., Gueraoui K., Kasmi M., 2009. Assessment of Seismic Vulnerability of Urban Buildings in Morocco., International Review of Physics (I.R.E.PHY.), 3 (1);

Ferreira, T. M., Vicente, R., Da Silva, J. M., Varum, H., Costa, A., 2013. Seismic vulnerability assessment of historical urban centres: case study of the old city centre in Seixal, Portugal. Bulletin of Earthquake Engineering, 11(5), p. 1753-1773;

Formisano A., Chieffo N., Mosoarca M., 2017. Seismic Vulnerability and Damage Speedy Estimation of an Urban Sector within the Municipality of San Potito Sannitico (Caserta, Italy). The Open Civil Engineering Journal, 11.1;

Formisano A., Florio G., Landolfo R., Mazzolani F. M., 2011. Un metodo per la valutazione su larga scala della vulnerabilità sismica degli aggregati storici, Anidis, Bari;
Formisano A., Mazzolani F. M., 2009. Vulnerabilità sismica di un aggregato in muratura in Sessa Aurunca. Atti del XIII Convegno ANIDIS. Bologna;

Giovinazzi S., Lagomarsino S., 2004. A Macroseismic Method for Vulnerability Assessment of Buildings. Proceedings of the 13th WCEE - World Conference on Earthquake Engineering, (896), p. 1-6;

GNDT, 1994. Rilevamento della vulnerabilità sismica degli edifici - Istruzioni per la compilazione della scheda di $2^{\circ}$ livello (Muratura), Gruppo Nazionale per la Difesa dai Terremoti, Roma;

Grünthal G., 1998. European macroseismic scale 1998. European Seismological Commission (ESC);

Maio R., Ferreira T. M., Vicente R., Estêvão J., 2016. Seismic vulnerability assessment of historical urban centres: Case study of the old city centre of Faro, Portugal. Journal of Risk Research, 19(5), 551-580;

Neves F., Costa A., Vicente,R., Oliveira C. S., Varum, H., 2012. Seismic vulnerability assessment and characterisation of the buildings on Faial Island, Azores. Bulletin of Earthquake Engineering, 10(1), p. 27-44;

Peláez J. A., Chourak M., Tadili B. A., Brahim L. A., Hamdache M., Casado C. L., Solares J. M., 2007. A catalog of main Moroccan earthquakes from 1045 to 2005. Seismological Research Letters, 78(6), p. 614-621.

Rossetto, T., Ioannou I., Grant D.N., Maqsood T., 2014. Guidelines for empirical vulnerability assessment, GEM Technical Report 2014-08 V1.0.0, GEM Foundation, Pavia, Italy;

Rovero L., Tonietti U., 2012. Criteri metodologici per l'intervento sul costruito storico a rischio sismico: istanze di sicurezza, istanze di salvaguardia e l'insegnamento delle culture costruttive locali. Convegno in onore del prof. Guido Sarà, Chianciano Terme, ottobre 2010, Firenze University Press, p. 289-300;

Vicente R., Parodi S., Lagomarsino S., Varum H., Silva J. M., 2011. Seismic vulnerability and risk assessment: case study of the historic city centre of Coimbra, Portugal. Bulletin of Earthquake Engineering, 9(4), p. 1067-109;

Vicente. R., 2008. Estratégias e Metodologias para Intervenções de Reabilitação Urbana - Avaliação da Vulnerabilidade e do Risco Sísmico do Edicado da Baixa de Coimbra. Phd thesis in seismic and structural engineering, University of Aveiro, Portugal; 